\title{
Fuzzy Reliability Analysis and Optimization Design of Hydraulic System of Bale Carrier for Tie Arm Device
}

\author{
Chenghui Pei ${ }^{*}$ Xingyan Liu, Zhigang Liu,Tong Zhang, and Guoliang Li \\ College of Mechanical Engineering, Inner Mongolia University of Technology, Huhehaote, 010051, China
}

\begin{abstract}
In order to realize the vertical and horizontal arrangement of square bales, the tie arm device adopts position feedback and hydraulic two-way lock loop for position control and position locking. The corresponding simulation model is established with AMESim software to verify the correctness of the model and to study the characteristics of the hydraulic control system. The fuzzy Failure Mode Effects and Criticality Analysis (FMECA) method is applied to the hydraulic system. According to the results of the hazard degree evaluation, the order of the hazard grade of each failure mode of the hydraulic system components is obtained and can be used for the reliability improvement and maintenance of the hydraulic system. The hydraulic control system is optimized by adjusting the parameters of several important influencing factors.
\end{abstract}

Keywords: horizontal push device; hydraulic system; AMESim; fuzzy comprehensive evaluation; FMECA

(Submitted on October 15, 2018; Revised on November 13, 2018; Accepted on December 14, 2018)

(C) 2019 Totem Publisher, Inc. All rights reserved.

\section{Introduction}

The bale stacker is mainly used for the collection, palletizing, and transportation of bales in the pasture production. The palletizing mechanism is a key structure of the bales stacker [1]. The function of the stacker is directly related to the palletizing quality and efficiency of the bales. In order to realize the vertical and horizontal arrangement of bales, a reasonable baling palletizing mechanism and its control system should be designed. The design of a reasonable hydraulic system is critical to make the palletizing mechanism complete palletizing quickly and accurately by using hydraulics as the power of the control system [2]. In this paper, the optimization model of hydraulic system is established by using AMESim software. By adjusting the parameters of several important factors, the dynamic characteristics of the hydraulic system are studied, and the liquid control system is optimized.

When the hydraulic system fails, it is usually difficult to directly observe, and the various causal relationships are complex. These effects make the fault location not only difficult to find, but also overlapping and intersecting between the faults and the causes. In addition, the service life of hydraulic components, hydraulic system operating environment, and other interference factors pose some challenges to troubleshoot the hydraulic system [3]. Failure Mode Effects and Criticality Analysis (FMECA) is a widely-used reliability analysis method. In terms of reliability analysis, the failure effects are critical. Researchers often describe the failure modes in fuzzy languages, such as the probability of occurrence, the detection, and the severity of the impact. The individual differences make qualitative descriptions subjective and inaccurate [4]. Many researchers have conducted in-depth studies in response to these problems.

Kellerc et al. [5] used fuzzy logic rules for reliability studies. Guimarães et al. [6] applied fuzzy inference systems to FMEA, which is of great significance for product reliability analysis. Bowles et al. [7] introduced fuzzy mathematics theory and proposed an evaluation method based on fuzzy mathematics. Dai et al. [8] used the fuzzy comprehensive evaluation

\footnotetext{
* Corresponding author.

E-mail address: peichh@126.com
} 
method to improve FMECA and solved its deficiencies in the reliability analysis of electro-hydraulic servo valves. Chen et al. [9] introduced fuzzy set theory into the reliability evaluation of industrial hydraulic systems, which reduced the failure rate of traditional fault prediction methods. Li et al. [10] applied a multi-level fuzzy comprehensive evaluation method to analyze civil aircraft electro-hydraulic servos. Hu et al. [11] combined fuzzy theory with traditional FMECA to analyze the influence and severity of failure modes of the hydraulic system of the amphibious armored vehicle. In this paper, the fuzzy theory is applied to FMECA methods, and the quantitative method is used to deal with the qualitative problem of describing the hazards of the failure modes. By adjusting the parameters of several more important influencing factors, the hydraulic control system is optimized.

\section{Square Bale Pusher Design}

In the harvesting machinery of square bale picking and stacking pallets, forage harvesting machinery mainly based on bales is commonly used in the Chinese market. However, its drawbacks are very obvious; for example, there is a single palletizing method, the process is cumbersome, and the palletizing efficiency is low. In order to overcome the drawbacks of domestic palletizing machinery as well as achieve better stacking efficiency of pallets, we designed a bale pusher as shown in Figure 1.



1. Square steel frame; 2. Slide rail block; 3. Lower swing arm; 4. Transverse thrust bar; 5. Drive shaft; 6. Lower shift bar; 7. Seat bearing; 8. Movable splint; 9. Drive shaft; 10. Upper arm rod; 11. Hydraulic cylinder; 12. Upshift rod; 13. Hexagonal nut; 14. Spacer; 15. Bolt; 16. Slide block seat Figure 1. Bale tie arm device

\section{Establishment of Hydraulic System Model of Tie Arm Device}

\subsection{Establishment of Hydraulic Model for Tie Arm Device}

To achieve the tie arm device in different positions of the lock, a two-way hydraulic lock is utilized. The bi-directional hydraulic lock shares a valve body and a control spool, the pilot-operated check valve is located on both sides, and the control spool is located in the middle. As shown in Figure 2, the two-way hydraulic lock works in the following manner: when the pressure oil from the A cavity goes to the left of the one-way valve into the A1 cavity and then through the control valve and right one-way valve, the original package and B1 cavity of the hydraulic oil are discharged through the B cavity. When the A and B cavities have no pressure oil, the conical valve conical valve and valve body close contact make the A1 and B1 cavities seal, and the implementing element is the bi-directional lock [12].

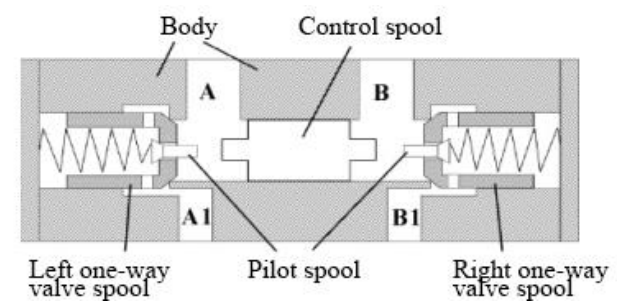

Figure 2. Bi-directional hydraulic lock schematic diagram

In this system, we use position feedback to control the tie arm device in different positions of the lock. The position sensor is used to change the position signal of the hydraulic cylinder. The position cycle is set by the position cycle sub-model. The working principle of the system is as follows: the specified position is compared with the feedback position of the sensor to generate the error value, and the error multiplied by the gain signal drives the servo valve to turn on or off the hydraulic oil supply of the actuator and change the oil feeding direction. The system can automatically adjust until the error is zero [13]. The system model is shown in Figure 3. 


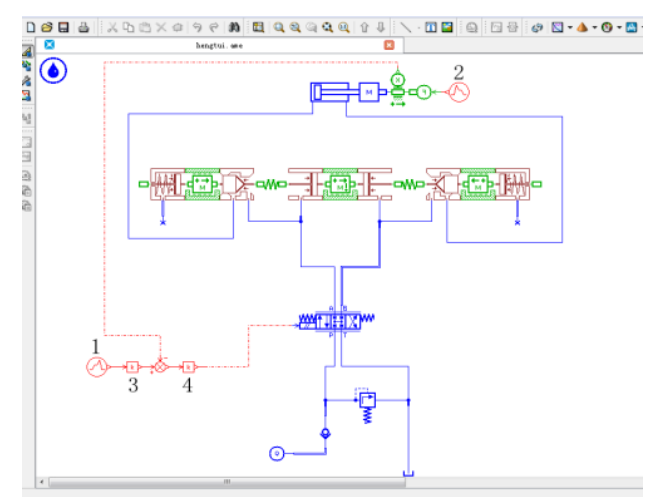

Figure 3. Tie arm device hydraulic system mode 1

\subsection{Basic Parameters Set}

The hydraulic system part of the important parameters set is shown in Table 1.

Table 1. Tie arm device subsystem parameters

\begin{tabular}{|c|c|c|}
\hline Parameters & Unit & Value \\
\hline Fuel flow & $\mathrm{L} / \mathrm{min}$ & 35 \\
\hline Safety valve opening pressure & $\mathrm{MPa}$ & 10 \\
\hline Hydraulic oil temperature & $\mathrm{Degc}$ & 40 \\
\hline Hydraulic oil density & $\mathrm{kg} / \mathrm{m}^{3}$ & 850 \\
\hline Directional valve to open the current & $\mathrm{Ma}$ & 200 \\
\hline Directional valve natural frequency & $\mathrm{Hz}$ & 50 \\
\hline Gain signal 1 value & & 10 \\
\hline Gain signal 2 value & & 250 \\
\hline Control valve core displacement limit & $\mathrm{M}$ & \pm 0.0045 \\
\hline Control spool damping & $\mathrm{N} / \mathrm{m} / \mathrm{s}$ & 1000 \\
\hline Conical valve taper & Degree & 60 \\
\hline One-way valve core quality & $\mathrm{kg}$ & 0.068 \\
\hline Check valve limit displacement & $\mathrm{M}$ & \pm 0.00628 \\
\hline One-way valve core spring stiffness & $\mathrm{N} / \mathrm{mm}$ & 130 \\
\hline Horizontal push cylinder piston rod diameter & $\mathrm{mm}$ & 56 \\
\hline Horizontal push hydraulic cylinder diameter & $\mathrm{mm}$ & 80 \\
\hline Displacement sensor output signal gain & $1 / \mathrm{m}$ & 10 \\
\hline
\end{tabular}

\subsection{System Model Verification}

In this paper, the simulation time is 12 seconds, the simulation step is 0.01 seconds, and the simulation results are shown in Figure 4.

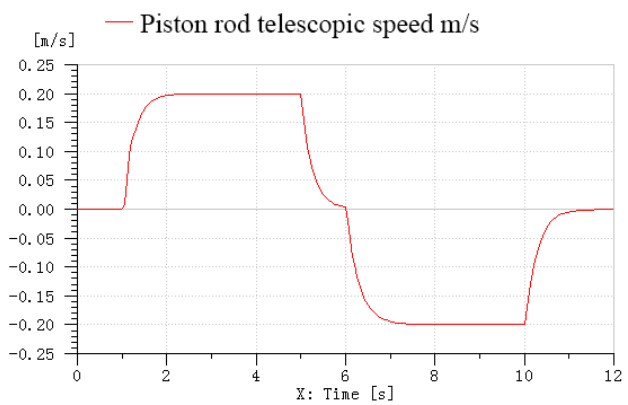

(a) Piston rod telescopic speed 


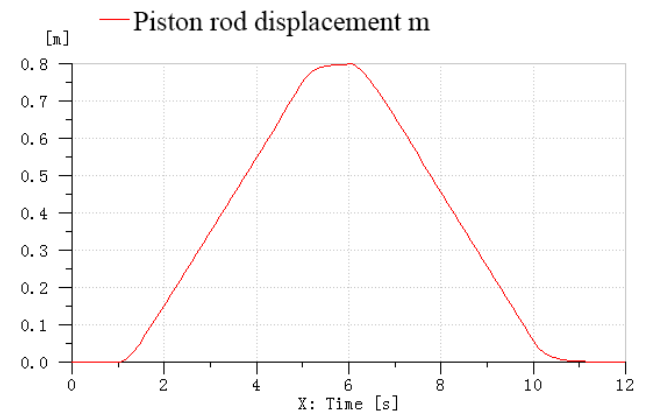

(b) Piston rod displacement

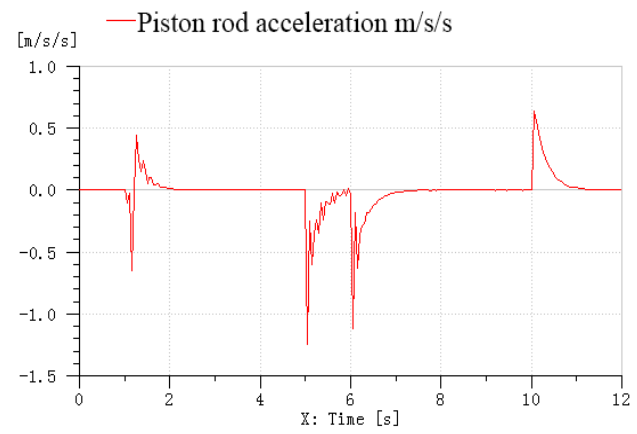

(c) Piston rod acceleration

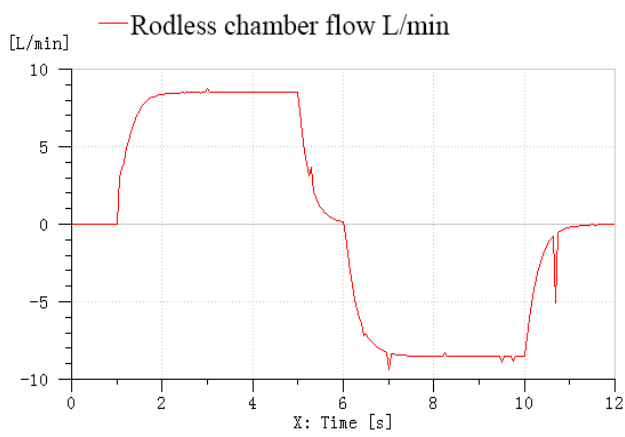

(d) Rodless chamber flow

Figure 4. Tie arm device subsystem simulation

As can be seen from Figure 4(a), the piston rod accelerates from $0.2 \mathrm{~m} / \mathrm{s}$ in $1 \sim 2$ seconds, stays steady at $2 \sim 5$ seconds, decelerates to $0 \mathrm{~m} / \mathrm{s}$ in $5 \sim 6$ seconds, and then the speed change of the piston rod retracts in $6 \sim 12$ seconds. The aforementioned process is similar to that of the extension; From Figure 4(b), the piston rod extending $0.8 \mathrm{~m}$ meets the actual situation. From Figure 4(c), the acceleration fluctuations greatly in the 1st, 5th, 6th, and 10th seconds. The piston rods either start from $0 \mathrm{~m} / \mathrm{s}$ or slow down at a steady speed, so the image is also conformity. From Figure 4(d), the inlet flow curve of the rodless cavity can match Figure 4(a) closely, so the hydraulic subsystem model is generally correct.

\section{Hengshui Device Hydraulic System Optimization}

\subsection{Control Parameter Optimization}

In AMESim, the dynamic characteristics of the three bit four way hydraulic servo valve spool are represented by a two order oscillatory system. Based on the automatic control principle, in the closed loop control system composed of the two order systems, the amplification factor of the preamplifier of the two order system has a great impact on the dynamic performance of the system. In this hydraulic subsystem, the preamplifier is represented by the gain 4 , and the value of the gain 4 is adjusted repeatedly. The displacements of actual output and the piston rod of the hydraulic cylinder are observed. Given the difference between the expected value and the actual value, it can be obtained that the smaller the difference, the better the performance. The optimal parameter [14], which makes the system performance the best state, is found. Here, a traditional method is used to set the value of gain 4 to 200, 300, 400, 500, 600, and 700. The simulation length is set to 12 seconds, the simulation step is 0.05 , and the batch mode is entered. 
The desired displacement is calculated with the result of the piston rod displacement obtained from the simulation. The results are shown in Figure 5.

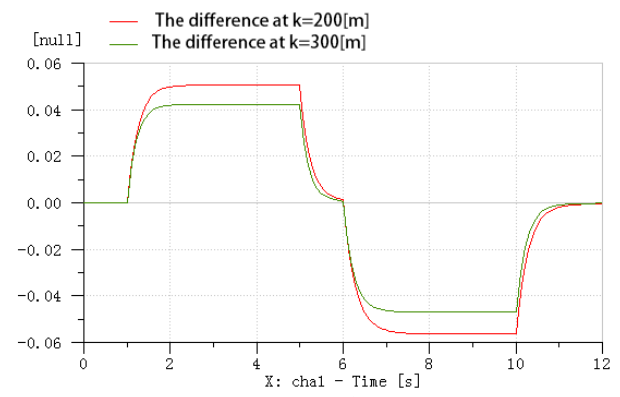

(a) $\mathrm{K} 4=200$ and $\mathrm{K} 4=300$

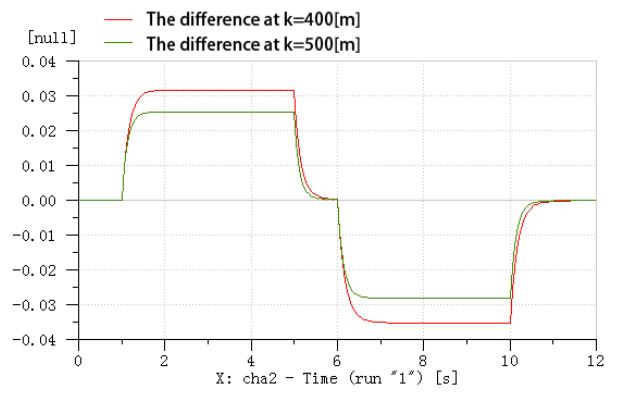

(b) $\mathrm{K} 4=400$ and $\mathrm{K} 4=500$

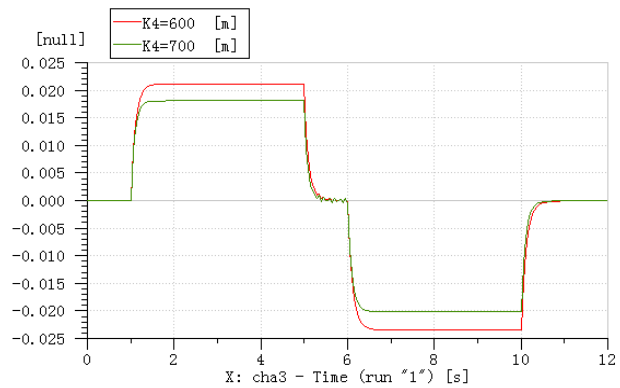

(c) $\mathrm{K} 4=600$ and $\mathrm{K} 4=700$

Figure 5. The difference between piston rod displacement and expected value under different $\mathrm{K} 4$ values

It can be observed from Figure 5(a) that when the K4 value is equal to 200, the dynamic error of the system is close to $0.06 \mathrm{~m}$, and it takes about $1 \mathrm{~s}$ for the system to reach a stable state. When the K4 value is equal to 700 , the dynamic error of the system is close to $0.02 \mathrm{~m}$, and the system only takes about $0.3 \mathrm{~s}$ to reach the steady state. Based on Figures 5(a), 5(b), and 5(c), it can be concluded that when K4 takes a greater value, the response of the system is faster and the dynamic error of the system is smaller.

As K4 takes a bigger value, however, it will cause overshoot of the following curve. The system will obviously oscillate and affect its own stability. We combine the curves under these different values and then perform local amplification, and the obvious difference is shown in Figure 6.

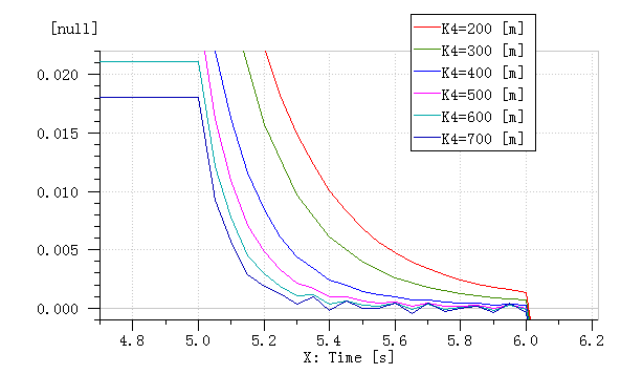

Figure 6. Local magnification of piston rod displacement and expected value difference under different K4 values 
From Figure 6, we can see that when the K4 value is 500, the system starts to oscillate within $5 \sim 6$ seconds. When the $\mathrm{K} 4$ takes the value of 700, the oscillation of the system within $5 \sim 6$ seconds is very obvious. With respect to both system error and stability, the value of gain 4 is repeated, and the optimum value range of K4 is $440 \sim 480$.

\subsection{Optimization of Structural Parameters}

Several key structural parameters of the bi-directional hydraulic lock (i.e., control valve core mass, one-way valve core mass, control valve core damping, and one-way valve core stiffness) are set and simulated. Compared with the control valve core and one-way valve core of the system, the control valve damping value and the size of the one-way valve stiffness of the entire system has a greater impact. Accordingly, the aforementioned two parameters are studied [15].

\subsubsection{Control Spool Damping Optimization}

By changing the damping value of the control valve core, the curve of piston rod extension time under different damping values can be simulated. The results are shown in Figure 7. The average pressure curve and flow curve of the hydraulic cylinder under different damping of the control valve core are shown in Figures 8 and 9, respectively.

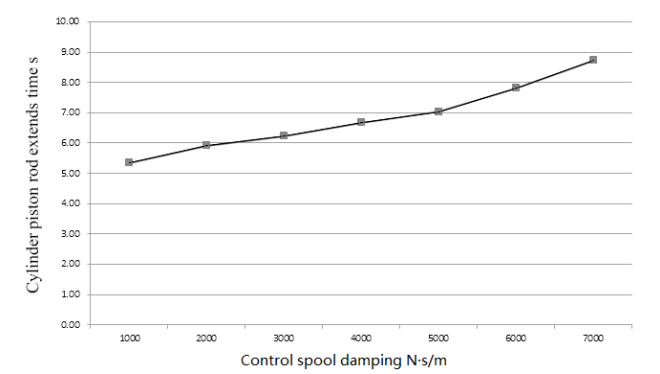

Figure 7. Different control spool damping hydraulic cylinder piston rod out of time

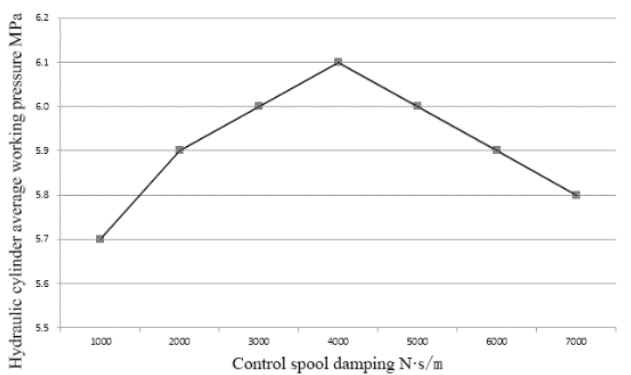

Figure 8. Different valve cylinder damping under the average working pressure cylinder

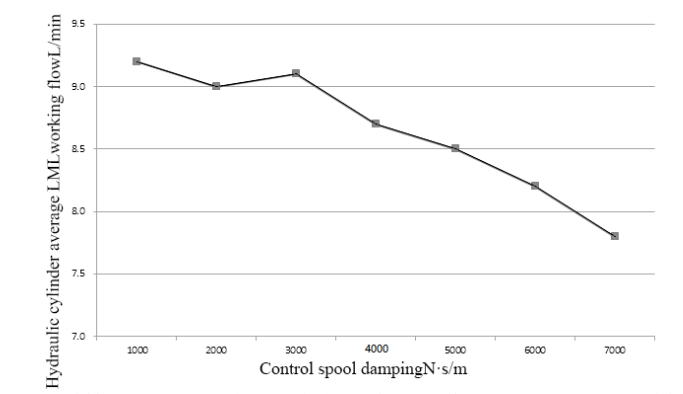

Figure 9. Different control spool damping cylinder average working flow

As can be seen from Figure 7, as the control spool damping increases, the hydraulic cylinder piston rod extension time becomes significantly larger and grows linearly, increasing from the initial 5.35 seconds to 8.72 seconds.

It can be seen from Figures 8 and 9 that the damping of the control valve core is between 1000 and $7000 \mathrm{~N} \cdot \mathrm{s} / \mathrm{m}$, and the average working pressure of the hydraulic cylinder does not change much and stays at 5.9MPa with little fluctuation. The hydraulic cylinder average flow decreases approximately from $9.2 \mathrm{~L} / \mathrm{min}$ to $7 \mathrm{~L} / \mathrm{min}$, which indicates that the increase in control valve damping results in the reduced speed of the hydraulic cylinder piston rod. The reason behind this is that the 
flow changes more smoothly, so the stability of the hydraulic cylinder piston rod speed is better.

After comprehensive analysis based on Figures 7-9, it can be obtained that when the control valve spool damping values stay within the range of $3000 \sim 4000 \mathrm{~N} \cdot \mathrm{s} / \mathrm{m}$, this can not only guarantee the piston rod out timely, but also maintain the stability of pressure as well as speed.

\subsubsection{One-Way Valve Core Spring Stiffness Optimization}

By changing the stiffness of the unidirectional valve core, the curve of the piston cylinder rod extension time under different unidirectional valve core stiffness can be simulated, as shown in Figure 10. The average pressure curve and average flow curve of the cylinder under different unidirectional valve core stiffness are shown in Figures 11 and 12, respectively.

From Figure 10, we can see that when the stiffness of the one-way valve core is below $150 \mathrm{~N} / \mathrm{mm}$, the extension time of the piston rod of the hydraulic cylinder basically remains at 5.3 seconds. When the stiffness is greater than $150 \mathrm{~N} / \mathrm{mm}$, the piston rod extension time is obviously longer. In addition, when the stiffness value is $400 \mathrm{~N} / \mathrm{mm}$, the piston extension time reaches 10.79 seconds. This indicates that the stiffness of the one-way valve spring has a great influence on the performance of the hydraulic cylinder.

It can be seen from Figure 11 that the mean working pressure increases when the spring rate is less than $150 \mathrm{~N} / \mathrm{mm}$. When the spring rate is greater than $150 \mathrm{~N} / \mathrm{mm}$, the average working pressure also increases. As can be seen from Figure 12, the flow rate of the hydraulic cylinder changes drastically with an increase in spring stiffness. Spring stiffness is in the range of $50 \sim 400 \mathrm{~N} / \mathrm{mm}$, and the cylinder flow quickly drops from $10.1 \mathrm{~L} / \mathrm{min}$ to $6.9 \mathrm{~L} / \mathrm{min}$. However, the cylinder flow changes more smoothly, which indicates that the piston rod protruding speed is relatively stable [16].

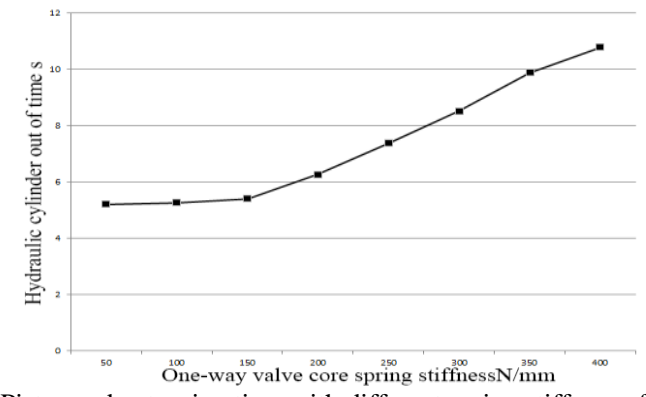

Figure 10. Piston rod extension time with different spring stiffness of check valve

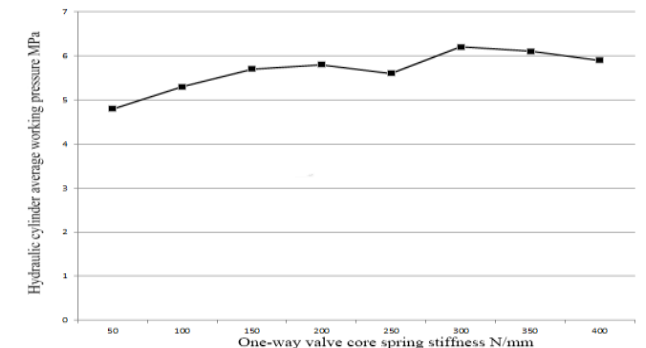

Figure 11. Average working pressure of hydraulic cylinder under different unidirectional valve core spring stiffness

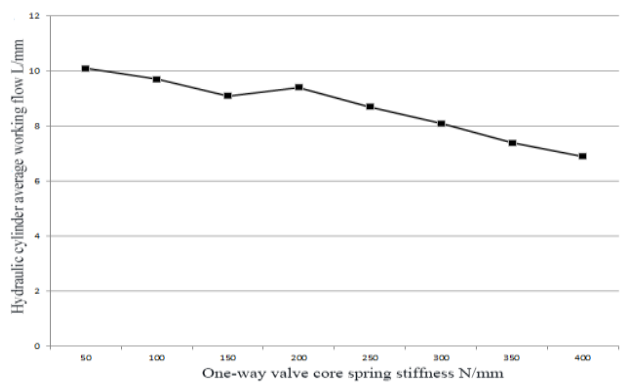

Figure 12. Average working flow of hydraulic cylinder under different unidirectional valve core spring stiffness

When the value of the check valve spring stiffness is in the range of $50 \sim 400 \mathrm{~N} / \mathrm{mm}$, select the range of one-way valve 
core stiffness as $100 \sim 150 \mathrm{~N} / \mathrm{mm}$. This can ensure that the piston rod extends in time, and it can also better ensure the pressure stability and speed stability.

\section{Fuzzy FMECA Method}

The fuzzy FMECA method combines the fuzzy comprehensive evaluation method and the FMECA method. The danger of the failure can be clearly manifested to make the traditional FMECA method more scientific [17].

The basic steps of the fuzzy FMECA method are as follows:

(1) Define a set of factors

The set of factors affect the object of evaluation, and different elements represent different influencing factors. Factor sets are usually represented by $\mathrm{U}$, that is,

$$
\mathrm{U}=\left\{u_{1}, u_{2}, \cdots, u_{i}, \cdots, u_{n}\right\}
$$

Where $u_{i}$ indicates the $i$ influence factor, $i=1,2, \cdots, n$.

(2) Set up the evaluation set

The evaluation set is usually indicated by V:

$$
\mathrm{V}=\left\{v_{1}, v_{2}, \cdots, v_{j}, \cdots, v_{m}\right\}
$$

Where $v_{j}$ indicates the $j$ rating, $j=1,2, \cdots, m$.

(3) Establish the fuzzy factor evaluation matrix

A fuzzy mapping $\mathrm{f}$ for $\mathrm{U}$ to $\mathrm{V}$ is given, $\mathrm{f}: \mathrm{U} \rightarrow \mathrm{F}(\mathrm{V}), u_{i} \rightarrow f\left(u_{i}\right)$, and $f\left(u_{i}\right)=r_{i}=\left(r_{i 1}, r_{i 2}, \cdots, r_{i j}, \cdots, r_{i m}\right)$, the fuzzy vector of evaluating $u_{i}, r_{i j}$ is the membership of the factor i factor $u_{i}$ at factor level $v_{j}$.

This article uses statistical methods to determine membership, an expert evaluation team composed of $h$ persons is established, each member evaluates one and only one evaluation grade $v_{j}$ for each influencing factor $u_{i}$ of a certain failure mode, and if the $h_{i j}$ member in the h team member evaluating $u_{i}$ belongs to $v_{j}$, then the $u_{i}$ 's evaluation set is obtained [18].

The $n$ failure modes of each factor evaluation set written by the fuzzy factor level evaluation matrix $\mathrm{R}$ are:

$$
\mathrm{R}=\left(R_{1}, R_{2}, \cdots, R_{n}\right)^{T}=\left[\begin{array}{cccc}
r_{11} & r_{12} & \cdots & r_{1 m} \\
r_{21} & r_{22} & \cdots & r_{2 m} \\
\vdots & \vdots & \ddots & \vdots \\
r_{n 1} & r_{n 2} & \cdots & r_{n m}
\end{array}\right]
$$

(4) Determine the weight of each factor set

Because each factor has a different influence on the failure, it is necessary to give the importance of each factor in the total evaluation during the process of comprehensive evaluation. The steps of using the analytic hierarchy process are described as follows:

$a_{i j}$ is used to represent the relative importance value of factor $u_{i}$ to $u_{j}$, and the standard reference Table 2 is taken to determine the matrix A [19]:

$$
\mathrm{A}=\left[\begin{array}{cccc}
a_{11} & a_{12} & \cdots & a_{1 m} \\
a_{21} & a_{22} & \cdots & a_{2 m} \\
\vdots & \vdots & \ddots & \vdots \\
a_{n 1} & a_{n 2} & \cdots & a_{n m}
\end{array}\right]
$$


Table 2. AHP judgment matrix scale and its meaning

\begin{tabular}{|c|c|}
\hline$a_{i j}$ & Meaning \\
\hline 1 & $u_{i}$ is as important as $u_{j}$ \\
\hline 3 & $u_{i}$ is slightly more important than $u_{j}$ \\
\hline 5 & $u_{i}$ is obviously more important than $u_{j}$ \\
\hline 7 & $u_{i}$ is more important than $u_{j}$ \\
\hline 9 & $u_{i}$ is more important than $u_{j}$ \\
\hline one of $2,4,6,8$ & The importance of $u_{i}$ to $u_{j}$ is between the equivalents \\
\hline
\end{tabular}

According to the judgment matrix $\mathrm{A}$, it calculates its maximum eigenvalue $\lambda_{\max }$ and its corresponding eigenvector $\xi=\left(x_{1}, x_{2}, \cdots, x_{n}\right)$. After normalization of the eigenvector, it can be used as the weight set $\mathrm{W}=\left(w_{1}, w_{2}, \cdots, w_{n}\right)^{T}$. Before normalization, the consistency test of the judgment matrix A must be performed to determine whether the weight distribution is reasonable. The consistency test formula is shown as

$$
\begin{array}{r}
R_{C}=I_{C} / I_{R} \\
I_{C}=\frac{\lambda_{\max }-n}{n-1}
\end{array}
$$

Where $R_{C}$ indicates the ratio of random consistency of the judgment matrix; $I_{C}$ indicates the random consistency index of the judgment matrix; $I_{R}$ is the average random consistency of the matrix indicators. Table 3 can be obtained:

Table 3. $I_{R}$ values of 1-13 order judgement matrix
\begin{tabular}{|c|c||c|c|}
\hline$n$ & $I_{R}$ & $n$ & $I_{R}$ \\
\hline 1 & 0.00 & 8 & 1.41 \\
\hline 2 & 0.00 & 9 & 1.45 \\
\hline 3 & 0.58 & 10 & 1.49 \\
\hline 4 & 0.90 & 11 & 1.52 \\
\hline 5 & 1.12 & 12 & 1.54 \\
\hline 6 & 1.24 & 13 & 1.56 \\
\hline 7 & 1.32 & & \\
\hline
\end{tabular}

When $R_{C}<0.1$, the judgment matrix A has a satisfactory consistency; otherwise, the elements in A should be modified to meet the requirements.

(5) A fuzzy comprehensive evaluation

Rewrite the set of failure mode factor weights as a vector mode.

$$
\mathrm{B}=\mathrm{W} \cdot \mathrm{R}=\left[w_{1}, w_{2}, \cdots, w_{n}\right] \cdot\left[\begin{array}{cccc}
r_{11} & r_{12} & \cdots & r_{1 m} \\
r_{21} & r_{22} & \cdots & r_{2 m} \\
\vdots & \vdots & \ddots & \vdots \\
r_{n 1} & r_{n 2} & \cdots & r_{n m}
\end{array}\right]=\left(b_{1}, b_{2}, \cdots, b_{n}\right)
$$

Where $\mathrm{B}$ is the fuzzy comprehensive evaluation vector to determine the failure mode.

(6) Determine the level of comprehensive hazard

In order to interpret the result more intuitively, B is processed by the weighted average method to obtain a simple numerical value $\mathrm{C}$ to represent the evaluation result, that is:

$$
\mathrm{C}=\mathrm{B} \cdot \mathrm{V}
$$

(7) Multi-level fuzzy comprehensive evaluation

The actual complex system consists of multiple subsystems. When we use multi-level fuzzy comprehensive evaluation, the first level fuzzy comprehensive evaluation of each sub-system failure mode is carried out, and the fuzzy comprehensive 
evaluation vector and comprehensive hazard level score are obtained. Then, system failure modes as a second-level fuzzy comprehensive evaluation of the factors are expressed as

$$
\mathrm{U}=\{\text { fault mode } 1 \text {, fault mode } 2, \cdots \text {, fault mode } k\}
$$

The level of factor $\mathrm{V}$ is the same, and then the weight set of each influencing factor is calculated by AHP. The comprehensive evaluation of the system is performed using the fuzzy comprehensive evaluation method. Through this method, we can obtain the second-level fuzzy comprehensive evaluation, and then the multi-level fuzzy evaluation of the system can be obtained.

\section{The Cross-Pushing Device Hydraulic System Fuzzy FMECA Analysis}

The design of the hydraulic control system is analyzed, combined with relevant information, servo valves, hydraulic cylinders, check valves, reversing valves, and piping in a liquid-controlled system. As an example, the fuzzy FMECA method is used to compute its reliability [20]. The FMECA tables of the five components are shown in Table 4.

Table 4. Hydraulic control system five parts FMECA table

\begin{tabular}{|c|c|c|c|c|c|c|c|c|}
\hline $\begin{array}{l}\text { Product } \\
\text { name }\end{array}$ & $\begin{array}{l}\text { Sequence } \\
\text { Number }\end{array}$ & $\begin{array}{c}\text { Failure } \\
\text { mode }\end{array}$ & Cause of issue & Local effects & High level impact & The final impact & $\begin{array}{c}\text { Severity } \\
\text { level }\end{array}$ & $\begin{array}{c}\text { Take } \\
\text { measures }\end{array}$ \\
\hline \multirow[t]{2}{*}{$\stackrel{0}{0}$} & 1 & $\begin{array}{l}\text { Slow } \\
\text { response, } \\
\text { slow } \\
\text { response }\end{array}$ & $\begin{array}{l}\text { Reduced oil } \\
\text { pressure }\end{array}$ & $\begin{array}{l}\text { Cylinder } \\
\text { instability }\end{array}$ & $\begin{array}{l}\text { Corresponding push, } \\
\text { dial action instability }\end{array}$ & $\begin{array}{c}\text { Tie arm device } \\
\text { stacking quality } \\
\text { decline }\end{array}$ & III level & $\begin{array}{l}\text { Increase the } \\
\text { pressure of oil } \\
\text { supply }\end{array}$ \\
\hline & 2 & $\begin{array}{l}\text { Vibration } \\
\text { appears }\end{array}$ & $\begin{array}{l}\text { The system gain } \\
\text { is too high }\end{array}$ & $\begin{array}{l}\text { Cylinder } \\
\text { instability }\end{array}$ & $\begin{array}{l}\text { Corresponding push, } \\
\text { dial action instability }\end{array}$ & $\begin{array}{c}\text { Tie arm device } \\
\text { stacking quality } \\
\text { decline }\end{array}$ & II level & $\begin{array}{c}\text { Reduce } \\
\text { system gain }\end{array}$ \\
\hline \multirow{4}{*}{ 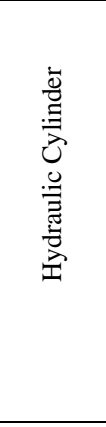 } & 3 & Leakage & Seal failure & $\begin{array}{l}\text { Cylinder lack } \\
\text { of thrust }\end{array}$ & $\begin{array}{c}\text { Corresponding to } \\
\text { push, dial performance } \\
\text { decline }\end{array}$ & $\begin{array}{c}\text { Tie arm device } \\
\text { stacking quality } \\
\text { decline }\end{array}$ & III level & $\begin{array}{c}\text { Replace the } \\
\text { seal }\end{array}$ \\
\hline & 4 & $\begin{array}{l}\text { Internal } \\
\text { leakage }\end{array}$ & Seals wear & $\begin{array}{l}\text { Cylinder } \\
\text { instability }\end{array}$ & $\begin{array}{c}\text { Corresponding to } \\
\text { push, dial performance } \\
\text { decline }\end{array}$ & $\begin{array}{c}\text { Tie arm device } \\
\text { stacking quality } \\
\text { decline }\end{array}$ & III level & $\begin{array}{l}\text { Replace the } \\
\text { seal }\end{array}$ \\
\hline & 5 & Crawl & $\begin{array}{c}\text { Hydraulic } \\
\text { cylinder } \\
\text { accumulates air }\end{array}$ & $\begin{array}{l}\text { Cylinder } \\
\text { instability }\end{array}$ & $\begin{array}{l}\text { Hydraulic cylinder life } \\
\text { is reduced }\end{array}$ & $\begin{array}{c}\text { Tie arm device } \\
\text { stacking quality } \\
\text { decline }\end{array}$ & III level & $\begin{array}{l}\text { Exhaust the } \\
\text { air }\end{array}$ \\
\hline & 6 & $\begin{array}{l}\text { Lack of } \\
\text { thrust }\end{array}$ & $\begin{array}{l}\text { Frictional } \\
\text { resistance is too } \\
\text { large }\end{array}$ & $\begin{array}{l}\text { Reduced } \\
\text { effective } \\
\text { traction } \\
\text { cylinder }\end{array}$ & $\begin{array}{l}\text { Corresponding push, } \\
\text { dial action instability }\end{array}$ & $\begin{array}{c}\text { Tie arm device } \\
\text { stacking quality } \\
\text { decline }\end{array}$ & III level & $\begin{array}{l}\text { Adjust the } \\
\text { cylinder and } \\
\text { piston with } \\
\text { the gap } \\
\end{array}$ \\
\hline  & 7 & $\begin{array}{c}\text { Oil is not } \\
\text { countercurr } \\
\text { ent }\end{array}$ & $\begin{array}{l}\text { Check valve } \\
\text { stuck }\end{array}$ & $\begin{array}{l}\text { Valve does } \\
\text { not work }\end{array}$ & $\begin{array}{l}\text { Corresponding push, } \\
\text { dial no corresponding } \\
\text { action }\end{array}$ & $\begin{array}{l}\text { Tie arm device to } \\
\text { stop working }\end{array}$ & II level & $\begin{array}{l}\text { Demolition, } \\
\text { cleaning } \\
\text { valve }\end{array}$ \\
\hline \multirow{2}{*}{  } & 8 & $\begin{array}{l}\text { Commutati } \\
\text { on is not } \\
\text { reliable }\end{array}$ & $\begin{array}{c}\text { Spring } \\
\text { deformation } \\
\text { fracture } \\
\end{array}$ & $\begin{array}{l}\text { Cylinder } \\
\text { instability }\end{array}$ & $\begin{array}{l}\text { Corresponding push, } \\
\text { dial action instability }\end{array}$ & $\begin{array}{c}\text { Tie arm device } \\
\text { stacking quality } \\
\text { decline }\end{array}$ & II level & $\begin{array}{l}\text { Adjust the } \\
\text { gap }\end{array}$ \\
\hline & 9 & $\begin{array}{l}\text { Commutati } \\
\text { on moves } \\
\text { slowly } \\
\end{array}$ & Poor lubrication & $\begin{array}{c}\text { Change the } \\
\text { valve } \\
\text { function }\end{array}$ & $\begin{array}{l}\text { Corresponding push, } \\
\text { dial action instability }\end{array}$ & $\begin{array}{c}\text { Tie arm device } \\
\text { stacking quality } \\
\text { decline } \\
\end{array}$ & III level & $\begin{array}{c}\text { Adjust the } \\
\text { viscosity of } \\
\text { the lubricant }\end{array}$ \\
\hline $\begin{array}{l}\stackrel{\varrho}{\Xi} \\
\stackrel{\Xi}{\cong}\end{array}$ & 10 & $\begin{array}{l}\text { Pipeline } \\
\text { blocked }\end{array}$ & Oil pollution & $\begin{array}{l}\text { Inadequate } \\
\text { supply of oil }\end{array}$ & Cylinder instability & $\begin{array}{c}\text { Tie arm device } \\
\text { stacking quality } \\
\text { decline }\end{array}$ & IV level & $\begin{array}{l}\text { Filter oil } \\
\text { impurities }\end{array}$ \\
\hline
\end{tabular}

The steps of the fuzzy FMECA analysis of hydraulic system are as follows:

(1) Set up a set of factors

For the failure of the hydraulic system for hazard assessment, the set of factors used are as follows: 
$\mathrm{U}=\{$ probability of failure, severity, ease of detection, ease of maintenance $\}$

(2) Set up an evaluation set

The factors are divided into four levels: $\mathrm{V}=\{1,2,3,4\}$. The different factors for the level of division are shown in Table 5.

Table 5. Factor ranking table

\begin{tabular}{|c|c|c|c|c|}
\hline Influencing factors & \multicolumn{4}{|c|}{ Grade } \\
\cline { 2 - 5 } & 1 & 2 & 3 & 4 \\
\hline Failure probability level $\left(u_{1}\right)$ & $\begin{array}{c}\text { rarely } \\
\text { happens }\end{array}$ & occasionally & $\begin{array}{c}\text { occasionally } \\
\text { happens }\end{array}$ & $\begin{array}{c}\text { happens very } \\
\text { often }\end{array}$ \\
\hline Severity level $\left(u_{2}\right)$ & $\begin{array}{c}\text { slight } \\
\text { influence }\end{array}$ & $\begin{array}{c}\text { medium } \\
\text { effect }\end{array}$ & $\begin{array}{c}\text { tremendous } \\
\text { influence }\end{array}$ & deadly impact \\
\hline $\begin{array}{c}\text { Detection level of difficulty } \\
\left(u_{3}\right)\end{array}$ & $\begin{array}{c}\text { accurate } \\
\text { detection }\end{array}$ & $\begin{array}{c}\text { not easy to } \\
\text { detect }\end{array}$ & hard to detect & $\begin{array}{c}\text { unable to } \\
\text { detect }\end{array}$ \\
\hline $\begin{array}{c}\text { Maintenance level of difficulty } \\
\left(u_{4}\right)\end{array}$ & $\begin{array}{c}\text { simple } \\
\text { debugging }\end{array}$ & re-install & replace parts & $\begin{array}{c}\text { unable to } \\
\text { repair }\end{array}$ \\
\hline
\end{tabular}

(3) Establish fuzzy evaluation matrix of failure mode

Ten experts proficient in the hydraulic system send the questionnaire. We have $R_{1}^{1}=\{0.1,0.5,0.4,0\}, R_{2}^{1}=$ $\{0.6,0.4,0,0\}$, detection of the level of difficulty level set $R_{3}^{1}=\{0.2,0.8,0,0\}$, and maintenance level of difficulty level set $R_{4}^{1}=\{0.9,0.1,0,0\}$. Therefore, the fuzzy factor evaluation matrix is

$$
\mathrm{R}^{1}=\left(R_{1}^{1}, R_{2}^{1}, R_{3}^{1}, R_{4}^{1}\right)^{T}=\left[\begin{array}{cccc}
0.1 & 0.5 & 0.4 & 0 \\
0.6 & 0.4 & 0 & 0 \\
0.2 & 0.8 & 0 & 0 \\
0.9 & 0.1 & 0 & 0
\end{array}\right]
$$

Similarly, we can get the fuzzy factor evaluation matrix of the remaining nine failure modes as

$$
\begin{aligned}
\mathrm{R}^{2} & =\left[\begin{array}{cccc}
0.2 & 0.7 & 0.1 & 0 \\
0 & 0.6 & 0.4 & 0 \\
0 & 0.8 & 0.2 & 0 \\
0 & 0.5 & 0.5 & 0
\end{array}\right] \\
\mathrm{R}^{3} & =\left[\begin{array}{cccc}
0.2 & 0.5 & 0.3 & 0 \\
0.7 & 0.3 & 0 & 0 \\
0.6 & 0.4 & 0 & 0 \\
0 & 0.2 & 0.6 & 0.2
\end{array}\right] \\
R^{4} & =\left[\begin{array}{cccc}
0.1 & 0.5 & 0.4 & 0 \\
0.6 & 0.4 & 0 & 0 \\
0 & 0.8 & 0.2 & 0 \\
0 & 0.3 & 0.4 & 0.3
\end{array}\right] \\
\mathrm{R}^{5} & =\left[\begin{array}{cccc}
0.2 & 0.6 & 0.2 & 0 \\
0 & 0.5 & 0.5 & 0 \\
0 & 0.9 & 0.1 & 0 \\
0.7 & 0.3 & 0 & 0
\end{array}\right] \\
\mathrm{R}^{6} & =\left[\begin{array}{cccc}
0.1 & 0.7 & 0.2 & 0 \\
0.6 & 0.4 & 0 & 0 \\
0 & 0.6 & 0.4 & 0 \\
0.4 & 0.6 & 0 & 0
\end{array}\right] \\
\mathrm{R}^{7} & =\left[\begin{array}{cccc}
0.2 & 0.4 & 0.4 & 0 \\
0 & 0.4 & 0.6 & 0 \\
0.2 & 0.5 & 0.3 & 0 \\
0.4 & 0.4 & 0.2 & 0
\end{array}\right]
\end{aligned}
$$




$$
\begin{aligned}
\mathrm{R}^{8} & =\left[\begin{array}{cccc}
0.3 & 0.3 & 0.4 & 0 \\
0 & 0.8 & 0.2 & 0 \\
0.2 & 0.6 & 0.2 & 0 \\
0.1 & 0.8 & 0.2 & 0
\end{array}\right] \\
\mathrm{R}^{9} & =\left[\begin{array}{cccc}
0.2 & 0.2 & 0.6 & 0 \\
0 & 0.4 & 0.6 & 0 \\
0 & 0.5 & 0.5 & 0 \\
0.1 & 0.8 & 0.1 & 0
\end{array}\right] \\
\mathrm{R}^{10} & =\left[\begin{array}{cccc}
0 & 0.1 & 0.4 & 0.5 \\
0.6 & 0.4 & 0 & 0 \\
0.3 & 0.5 & 0.2 & 0 \\
0.9 & 0.1 & 0 & 0
\end{array}\right]
\end{aligned}
$$

(4) Determine the weight set

Firstly, the factor weight set of failure mode 1 is solved. According to Tables 2 and 4, the relative importance of the four influencing factors of failure mode 1 are determined. The data are shown in Table 6.

Table 6. Failure mode 1 the relative importance and weight of each influencing factor
\begin{tabular}{|c|c|c|c|c|}
\hline Influencing factors & $u_{1}$ & $u_{2}$ & $u_{3}$ & $u_{4}$ \\
\hline$u_{1}$ & 1 & 3 & 7 & 5 \\
\hline$u_{2}$ & $1 / 3$ & 1 & 5 & 3 \\
\hline$u_{3}$ & $1 / 7$ & $1 / 5$ & 1 & $1 / 3$ \\
\hline$u_{4}$ & $1 / 5$ & $1 / 3$ & 3 & 1 \\
\hline
\end{tabular}

Table 6 can be obtained by the failure mode 1 judgment matrix $A^{1}$ :

$$
A^{1}=\left[\begin{array}{cccc}
1 & 3 & 7 & 5 \\
1 / 3 & 1 & 5 & 3 \\
1 / 7 & 1 / 5 & 1 & 1 / 3 \\
1 / 5 & 1 / 3 & 3 & 1
\end{array}\right]
$$

From the MATLAB software, the maximum eigenvalue of the $4 \times 4$ judgment matrix $A^{1}$ is 4.1170 , and the corresponding eigenvector is $\xi=[0.8880,0.4121,0.0869,0.1847]$. Before the normalization, the judgment matrix A must be consistent. The sex test is to determine whether the distribution of weights is reasonable. If it is not, it is necessary to consult related experts again and combine relevant data to modify the relative importance of each influencing factor until the results meet the requirements.

Consistency test:

$$
I_{C}=\frac{\lambda_{\max }-n}{n-1}=\frac{4.1170-4}{4-1}=0.039
$$

Since the judgment matrix $\mathrm{A}^{1}$ is 4 th order, the value of $I_{R}$ that can be found in Table 3 is 0.90 .

$$
R_{C}=I_{C} / I_{R}=0.039 / 0.90=0.0433
$$

Since $R_{C}=0.0433<0.1$, the judgment matrix $A^{1}$ has a satisfactory consistency. Therefore, the normalized feature vector $\xi=[0.8880,0.4121,0.0869,0.1847]$ corresponding to the maximum eigenvalue 4.1170 can be used as a weight set $\mathrm{W}$ for each factor. As can be seen from above, the sum of the eigenvectors is not 1 , so the eigenvectors are divided by the sum of these vectors, and the re-derived number is the weight vector. That is:

$$
\begin{aligned}
& \mathrm{W}_{1}=\xi_{1} / S=0.8880 /(0.8880+0.4121+0.0869+0.1847)=0.8880 / 1.5717=0.5650 \\
& \mathrm{~W}_{2}=\xi_{2} / S=0.4121 /(0.8880+0.4121+0.0869+0.1847)=0.4121 / 1.5717=0.2622
\end{aligned}
$$




$$
\begin{aligned}
& \mathrm{W}_{3}=\xi_{3} / S=0.0869 /(0.8880+0.4121+0.0869+0.1847)=0.0869 / 1.5717=0.0533 \\
& \mathrm{~W}_{4}=\xi_{4} / S=0.1847 /(0.8880+0.4121+0.0869+0.1847)=0.1847 / 1.5717=0.1175
\end{aligned}
$$

Thus, the factor weight set for failure mode 1 is

$$
W^{1}=\left[\mathrm{W}_{1}, \mathrm{~W}_{2}, \mathrm{~W}_{3}, \mathrm{~W}_{4}\right]=[0.5650,0.2622,0.0553,0.1175]
$$

The same weight set is used for the influence factors of each failure mode:

$$
W^{1}=W^{2}=W^{3}=W^{4}=W^{5}=W^{6}=W^{7}=W^{8}=W^{9}=W^{10}
$$

(5) A fuzzy comprehensive evaluation

The first-level fuzzy comprehensive evaluation of failure mode 1 can be obtained by Equation (7):

$$
B^{1}=W^{1} R^{1}=[0.3306,0.4434,0.2260,0]
$$

Empathy:

$$
\begin{gathered}
B^{2}=W^{2} R^{2}=[0.1130,0.6558,0.2312,0] \\
B^{3}=W^{3} R^{3}=[0.3297,0.4068,0.2400,0.0235] \\
B^{4}=W^{4} R^{4}=[0.2138,0.4669,0.2841,0.0353] \\
B^{5}=W^{5} R^{5}=[0.1953,0.5551,0.2496,0] \\
B^{6}=W^{6} R^{6}=[0.2608,0.6041,0.1351,0] \\
B^{7}=W^{7} R^{7}=[0.1711,0.4055,0.4234,0] \\
B^{8}=W^{8} R^{8}=[0.1923,0.5064,0.3130,0] \\
B^{9}=W^{9} R^{9}=[0.1248,0.3395,0.5357,0] \\
B^{10}=W^{10} R^{10}=[0.2797,0.2008,0.2371,0.2825]
\end{gathered}
$$

(6) A comprehensive level of hazard

From Equation (8), the comprehensive hazard level of fault mode 1 is $C^{1}=B^{1} \cdot V^{T}=1.8954$. Similarly, the remaining nine kinds of failure modes of the comprehensive degree of risk are $C^{2}=2.1182, C^{3}=1.9573, C^{4}=2.1411$, $C^{5}=2.0543, C^{6}=1.8743, C^{7}=2.2523, C^{8}=2.1441, C^{9}=2.4109$, and $C^{10}=2.5226$.

According to the level of the integrated hazard level, the fault modes 1 to 10 may be ranked according to their degree of danger as follows [5]: fault mode $10>$ fault mode $9>$ fault mode $7>$ fault mode $8>$ fault mode $4>$ fault mode $2>$ fault mode $5>$ fault mode $3>$ fault mode $1>$ fault mode 6 .

(7) Two-level fuzzy comprehensive evaluation

For the servo valve, the set of factors $U_{1}^{\prime}=\{$ failure mode 1 , failure mode 2$\}$, the evaluation set $V^{\prime}=\{1,2,3,4\}$, and the evaluation matrix $R_{1}^{\prime}=\left[B^{1}, B^{2}\right]$. According to the importance of these two failure modes, AHP [14] can be used to draw the weight set $W_{1}^{\prime}=\{0.167,0.833\}$, and the result of level 2 comprehensive evaluation is $B_{1}^{\prime}=W_{1}^{\prime} \cdot R_{1}^{\prime}=[0.1493,0.6203,0.2303,0]$, and the comprehensive hazard level is $C_{1}^{\prime}=B_{1}^{\prime} \cdot V^{T}=2.0808$. For the hydraulic cylinder, the comprehensive evaluation result and the comprehensive hazard degree can be respectively calculated as $B_{2}^{\prime}=[0.2838,0.4539,0.2398,0.0225]$ and $C_{2}^{\prime}=2.001$. For the check valve, the comprehensive evaluation result and comprehensive hazard degree can be respectively calculated as $B_{3}^{\prime}=[0.1711,0.4055,0.4234,0]$ and $C_{3}^{\prime}=2.2523$. For the 
directional control valve, the comprehensive evaluation result and the comprehensive hazard degree can be respectively calculated as $B_{4}^{\prime}=[0.1839,0.4855,0.3409,0]$ and $C_{4}^{\prime}=2.1776$. For the pipeline, the comprehensive evaluation results and the comprehensive hazard degree can be respectively calculated as $B_{5}^{\prime}=[0.2797,0.2008,0.2371,0.2825]$ and $C_{5}^{\prime}=$ 2.5226 .

According to the size of the integrated hazard, it can be seen that the arrangement of the five components with higher hydraulic system failure rate is: Piping > Check valve > Directional valve > Servo valve > Hydraulic cylinder. The most dangerous failure mode in the pipeline is the pipeline blockage. The servo valve in the most dangerous mode of failure is the emergence of vibration that is followed by the slow reaction. For the hydraulic cylinder, the failure mode of danger from large to small arrangement is: internal leakage, crawling, leakage, and lack of thrust.

The same method can be used to calculate the breakdown of the other components of the hydraulic system.

\section{Conclusions}

(1) Through the working principle of the bale pusher device, the model and parameters of the hydraulic system are built and simulated in the AMESim software. The simulation results show that the model is consistent with the actual situation.

(2) The combination of fuzzy theory and FMECA method overcomes the shortcomings of FMECA, quantifies the ambiguity index, and comprehensively evaluates these indicators using the quantitative calculation method, which can provide evaluation results that are more suitable for practical applications and reference for the further improvement of the reliability of the hydraulic system of the horizontal push device.

(3) By changing the control parameters and structural parameters, the structural parameters of the system are successfully optimized. The simulation results show that the optimal range of the preamplifier K4 is 440-480, the damping coefficient of the control valve core is $3000 \sim 4000 \mathrm{~N} \cdot \mathrm{s} / \mathrm{m}$, and the stiffness of the one-way valve core is $100-150 \mathrm{~N} / \mathrm{mm}$.

\section{References}

1. M. S. Yang and J. M. Du, "Grassland Engineering Mechanics," China Agricultural University Press, Beijing, 2013

2. S. D. Yang and G. X. He, "Hydraulic Transmission and Pneumatic Transmission," Huazhong University of Science and Technology Press, Wuhan, 2008

3. J. Y. Zhao and Y. C. Yao, "Research Progress of Hydraulic System Reliability," China Journal of Hydraulic Pneumatic and Sealing, No. 3, pp. 50-52, 2006

4. C. L. Ao, X. Z. Zheng, Y. Z. Dai, et al., "Tractor Use Reliability Fuzzy Comprehensive Evaluation," China Journal of Journal of Agricultural Mechanization, No. 4, pp. 84-87, 2004

5. A. Z. Kellerc and K. Z. Beng, "Further Applications of Fuzzy Logic to Reliability Assessment and Safety Analysis," Microelectronics Reliability, Vol. 29, No. 3, pp. 399-404, 1989

6. A. C. F. Guimarães and C. M. F. Lapa, "Effects Analysis Fuzzy Inference System in Nuclear Problems using Approximate Reasoning," Annals of Nuclear Energy, Vol. 31, No. 1, pp. 107-115, 2004

7. J. B. Bowles and C. E. Pelaez, "Fuzzy Logic Prioritization of Failures in a System Failure Mode, Effects and Criticality Analysis," Reliability Engineering \& Systems Safety, Vol. 50, No. 2, pp. 203-213, 1995

8. C. G. Dai, X. D. Wang, X. Zhang, and L. Wang, "Fuzzy Comprehensive Evaluation in FMECA of Electro-Hydraulic Servo Valve," China Journal of Journal of Beijing University of Aeronautics and Astronautics, Vol. 37, No. 12, pp. 1575-1578, 2011

9. D. Chen, C. Yao, and Z. Feng, "Reliability Prediction Method of Hydraulic System by Fuzzy Theory," IFAC Proceedings Volumes, Vol. 46, No. 5, pp. 457-462, 2013

10. P. Li, Z. H. Yuan, and F. Su, "Reliability Analysis of Electrohydraulic Servo Actuator based on Fuzzy FMECA," Machine Tools \& Hydraulics, Vol. 41, No. 13, pp. 178-182, 2013

11. Q. G. Hu and X. X. Shen, "Fuzzy Reliability Analysis in FMECA of Amphibious Armored Vehicle Hydraulic System," China Journal of Machine tools and hydraulic, Vol. 45, No. 13, pp. 16-173, 2017

12. Y. H. Liu and J. S. Chen, "Application of AMESim Simulation Technology in Design Analysis of Hydraulic System," Hydraulics \& Pneumatics, No. 11, pp. 1-6, 2015

13. W. T. Shi, Y. Q. Lu, Y. Lu, et al, "Design and Simulation of Hydraulic Transmission of Potato Harvester based on AMESim," Journal of Agricultural Mechanization Research, Vol. 40, No. 8, pp. 254-257, 2018

14. K. Zhang, X. D. Huang, Z. F. Xie, and M. Zhou, "Design and Optimization of a Novel Electrically Controlled High Pressure Fuel Injection System for Heavy Fuel Aircraft Piston Engine," Chinese Journal of Aeronautics, 2018

15. L. Wang, P. Zhou, M. L. Xia, et al, "Structural Optimization and Simulation of Marine Hydraulic Damper based on AMESim," Hydraulic \& Pneumatics, No. 6, pp. 94-98, 2018

16. Z. Zhou, D. Z. Ma, X. Y. Yu, et al, "Application of Fuzzy FMECA in Analysis of Product Reliability," China Journal of Electric Machines and Control, Vol. 14, No. 10, pp. 89-94, 2010 
17. V. R. Renjith, M. J. Kalathil, P. H. Kumar, and D. Madhavan, "Fuzzy FMECA (Failure Mode Effect and Criticality Analysis) of LNG Storage Facility," Journal of Loss Prevention in the Process Industries, Vol. 56, pp. 537-547, 2018

18. S. Carpitella, A. Certa, J. Izquierdo, and C. M. L. Fata, "A Combined Multi-Criteria Approach to Support FMECA Analyses: A Real-World Case," Reliability Engineering \& System Safety, pp. 169, 2018

19. Y. Wang and B. Cheng, "Fuzzy FMECA based on Common Faults of Wind Turbine Generator," Power System Protection \& Control, 2018

20. B. Goo, J. Lee, S. Seo, D. Chang, and H. Chung, "Design of Reliability Critical System using Axiomatic Design with FMECA," International Journal of Naval Architecture \& Ocean Engineering, 2017 